\title{
The 'Intergenerational Stake Hypothesis' in Indonesia and Germany
}

\section{Adult Daughters' and their Mothers' Perception of their Relationship}

\author{
Gisela Trommsdorff \\ University of Konstanz, Germany \\ Beate Schwarz \\ University of Basle, Switzerland
}

\begin{abstract}
The aim of this study is to test the general hypothesis that parents and their children systematically differ with respect to the perception of their relationship as described by the literature on the 'intergenerational stake'. To this end, the study compared 100 dyads of adult daughters and elderly mothers from Indonesia and Germany. Mothers and daughters were interviewed with respect to their value orientations and their evaluation of the present mother-daughter relationship. The results demonstrated that the 'intergenerational stake' hypothesis could be replicated for different aspects of the relationship quality in the German sample as compared to the Indonesian sample. Besides a pattern of motherdaughter differences consistent with the 'intergenerational stake hypothesis', two groups with different patterns were found: one group in which daughters perceived the relationship as more positive than mothers and another group characterized by low maternal self-disclosure. Culture and mothers' collectivism were associated with the assignment to the latter group. The results are interpreted in a culture-informed theoretical framework of intergenerational relations.
\end{abstract}

keywords: culture $\uparrow$ individualism-collectivism $\downarrow$ intergenerational relations life span $\downarrow$ self-disclosure $\uparrow$ values

\section{Introduction}

The study of intergenerational relations has recently gained in importance since massive demographic and socioeconomic changes all over the world 
may affect the way generations are linked to each other. Due to the still increasing longevity in most parts of the world, people have to face the fact that the amount one's lifetime overlaps with one's parents' lifetime is greater than in the past. This is related to various questions of solidarity between the generations, such as patterns of intergenerational assistance, systems of family eldercare, quality of intergenerational relations over time and similarities and differences between the generations with respect to values and mutual perception. Therefore, the study of intergenerational relations is of increasing importance. However, developmental and crosscultural studies on intergenerational relations are still rare.

The topic of intergenerational relationships has been mostly confined to parent-child relationships in early childhood and adolescence. Only recently has a life course perspective shifted the focus on parent-child relationships to later developmental ages including ageing parents and their adult children (e.g. Schaie and Willis, 1995). These studies have been confined to western samples. Particularly, comparative research focusing on different cultures outside the western industrialized areas is still lacking. It is as yet unknown whether in less individualistic cultures the same or different patterns of intergenerational relations, asymmetry in parent- child perception and family eldercare can be observed. In order to answer these questions, a cultureinformed approach to the issue of intergenerational relations is needed.

\section{The Intergenerational Stake Hypothesis}

How can the quality of intergenerational relations be described? 'Objective' indicators have often been used to measure the closeness of the relationship such as the frequency of contact or the geographical distance between parents and their children. 'Subjective' criteria of the relationship quality focus on the subjective perception and evaluation of the relationship by the respective partners (parents, children). The latter approach offers information about the quality of the relationship from the subjective perspectives of both partners, which may be similar or may differ.

A systematic bias in subjective evaluation with respect to the perception of the parent-child relationship was reported several decades ago by Bengtson and Kuypers (1971) in studies on middle-aged parents and their adolescent children. Parents consistently reported higher levels of closeness and harmony in the parent-child relation compared to their children. The authors suggested the 'developmental stake hypothesis' to explain this phenomenon. They regarded such systematic differences as a result of different developmental concerns of each generation, which were assumed to influence a different 'stake' in the intergenerational relationship. Parents are more interested in a stable continuation of positive relationships in the family including continuity of values, and so tend to overstate the positivity of their relationship with their children. In 
contrast, adolescent children who intend to become independent from their parents may feel less commitment to the parents and overstate negative aspects in their relationship to their parents. Differences in the goals and needs of the parents and the adolescent children depend on the respective developmental age. Thus, the phenomenon of perceptual differences may be a result of 'developmental stake'. Therefore, the question is whether this difference in perception of parent-child relationships is confined to adolescent children and their parents, or whether such differences also occur in later development, e.g. for adult children (who are parents themselves) and their elderly parents, who may increasingly face the need for assistance from their adult children. The question thus is whether past and expected future investment of parents and children in their relationship affects their mutual perception of their relationship.

In order to take into account sociocontextual influences from a life course approach, the individual-level 'developmental stake hypothesis' was changed to the sociostructural-level 'generational stake' and thereafter to the 'intergenerational stake hypothesis' (Giarrusso et al., 1995). This revised approach predicts more positive perceptions of parent-child relationships by parents as compared to children across the life span. The cross-generational perceptual difference is explained by both differential investment and also by differential development. Giarrusso et al. (1995) examined the intergenerational stake hypothesis in a longitudinal study of grandparents, parents and young adult children 20 years after the first measurement. Their measures included parents' and children's perception of the emotional quality of the relationship and they also took into account gender differences. Their data supported the original intergenerational stake hypothesis to a large degree. The authors explained their findings on the basis of the generational lineage position and rejected the explanation of the individual developmental stage.

Further studies on the intergenerational stake hypothesis revealed more than simple mean differences. Besides the parent-child dyads, which are characterized by a more positive view of the relationship by the parents compared to their children, there is a substantial number of parent-child dyads in these studies with a high intergenerational agreement as well as with a more positive evaluation by the children than by their parents (Aquilino, 1999; Giarrusso et al., 1995).

However, the question arises whether such differences in the perception of the relationship between parents and their children are a universal phenomenon or are affected by the sociocultural context. So far, there has been little empirical work on cross-cultural variations or similarities in intergenerational perceptions of the parent-child relationship. A study by Bond and Harvey (1991), comparing Mennonites and non-Mennonites in the US, found that adult children in both groups reported less family 
solidarity than the parents, with somewhat larger differences in the Mennonite group. However, the situation of Mennonites who live within a dominant culture to which the younger generation may want to adapt represents a specific problem in acculturation and minority research.

The present study deals with the question of whether the often replicated asymmetry in the perception of parent-child relations also occurs in cultures where parent-child relations are based on relatively stable values of mutual reciprocity and connectedness, and where independence is less valued. The question is whether other patterns of intergenerational differences prevail in a non-western cultural setting. This study thus is expected to contribute to the general research question whether the intergenerational stake hypothesis is a universal or a culture-specific phenomenon.

\section{Intergenerational Relationships from a Cross-Cultural Perspective}

Empirical data from anthropological and cross-cultural studies clearly contradict the assumption that adolescents and young adults universally try to achieve autonomy and independence from their parents (Dasen, 2007; Rothbaum and Trommsdorff, 2007; Trommsdorff, 1995). In some cultures, a preference for independence and autonomy is highly valued, whereas in other cultures interdependence and relatedness are preferred (Markus and Kitayama, 1991, 1994). This distinction of culture-specific value orientations has proven useful for the explanation of cultural differences in self-development, in the development of emotions and cognitions, and the development of interpersonal interactions and relations (Fiske et al., 1998; Greenfield et al., 2003; Kitayama et al., 2004; Mesquita and Markus, 2004; Rothbaum et al., 2000; Trommsdorff, 2006).

This differentiation between cultures is based on the influential studies of Hofstede $(2000,2007)$, who attempted to identify five dimensions underlying the value orientations prevalent in different countries. Hofstede's distinction between individualism and collectivism has become the most frequently cited. Accordingly, cultures differ with respect to a predominance of individualistic or collectivistic values. On the individual level, differences with respect to allocentrism and idiocentrism (Triandis, 1995) can (but not necessarily) coincide with membership in individualistic and collectivistic cultures. Several studies have pointed out that it is much too simple to conceive of this concept as only one dimension with two opposite poles (e.g. Kağitçibaşi, 1996; Oyserman et al., 2002).

What do these cultural values mean for research on intergenerational relationships, particularly with regard to the intergenerational stake hypothesis?

One may assume that higher values of independence as compared to interdependence among people in a culture may lead to fewer similarities between the generations than in cultures where people favour interdependence 
between family members. Accordingly, it might be that in highly industrialized and modernized, as compared to traditional, countries, more intergenerational differences in value orientations develop, since values change rapidly, and mobility is high. In line with this assumption, a comparison between German and Indonesian samples found that German adult daughters and their mothers differed considerably with respect to values regarding developmental timetables, while the Indonesian dyads shared the same value orientations (Schwarz et al., 2002). However, it is unclear whether value orientations and respective similarities in parent-child dyads are related to a bias regarding the perception of the parent-child relationship.

Parents in individualistic cultures as compared to their counterparts in collectivistic cultures may differ from their children in other aspects as well, including the positive evaluation of their relationship with their children. In line with the intergenerational stake hypothesis, they may overestimate the positive aspects of their relationship with their children. Thus, it is assumed that in cultures where preferences for values of individualism/independence prevail as compared to cultures with a preference for values of collectivism/interdependence, the discrepancies in the perception of parent-child relationships are higher, and that these are based on a bias towards a relatively more positive perception by the parents and a bias towards a relatively more negative perception by the adult children.

\section{Cultural and Sociodemographic Characteristics of Germany and Indonesia}

In order to test this assumption by means of a cross-cultural comparison, we included German and Indonesian samples for the following reasons. Both countries differ strongly in sociodemographic characteristics relevant for intergenerational relationships. With regard to urbanization, in Indonesia about 40 percent of the population lives in cities, while in Germany the proportion is almost 88 percent. The household size also differs. In Indonesia, as compared to Germany, both the proportion of households with more than two generations and the average number of children ( $2.8 \mathrm{vs} 1.3$ children per woman) are higher. In Indonesia, an average household consists of 4.5 persons, in Germany of only 2.2 persons. The actual average life expectancy in Indonesia is lower, with 66 years for women and 62 years for men, compared with 80 years for women and 74 years for men in Germany (United Nations Statistics Division, 2004; for further information, see Albert et al., 2005).

With regard to value orientations, only a few studies on value orientations have included Indonesia. The religious orientation in the two countries differs significantly, with a mostly Islamic (about 90 percent) population on Java (Indonesia) and a mostly Christian but secular population in Germany. According to Hofstede (2000), Indonesia was low in 
individualism and Germany was moderately high (14 vs 67 on a scale ranging from 0 to 100). Indonesia, like other Asian countries, and in contrast to Germany, was characterized by large 'power distance' (acceptance of exertion of power) but weak 'uncertainty avoidance'. Furthermore, Indonesians as compared to Germans showed less 'masculinity' orientation, which indicates a stronger emphasis on serving others and striving for consensus. Thus, we expect that among our participants from Germany the preference for values of individualism and independence should be more pronounced than in the Indonesian sample, whereas the preference for values of collectivism and interdependence should be more pronounced in the Indonesian sample.

In western countries like Germany, parent-child relationships are rather structured on the basis of equal partnership where reciprocal acceptance and exchange are based on individualism and independence (Rothbaum et al., 2000; Trommsdorff and Kornadt, 2003). In traditional Asian countries like Indonesia, parent-child relationships are hierarchically structured and at the same time characterized by emotional closeness and filial piety based on interdependence (Geertz, 1961, 1974; Mulder, 1992, 1996). In Indonesia, many ethnic minorities still carry on their traditional beliefs even though social changes have occurred (Williams, 1991). However, at the same time, one may generalize that the Indonesian population is characterized by predominating socially oriented values and traditions.

In our study we included a sample from West Java (mostly adhering to the Sundanese and partly to the Javanese culture). According to Javanese ethics, attaining the right rasa (moral attitude and behaviour) is the most important goal in life. 'A right rasa means that one is perfectly, or harmoniously, embedded in reality and, therefore, it implies the fulfillment of social and individual duties' (Magnis-Suseno, 1997: 200).

Parents and children in Indonesia occupy different roles; both strive to fulfil their well-known duties in a context of social harmony; since the parent-child relationship is clearly structured, no significant differences in mutual perception of the relationship are expected. This is in contrast to German parent-child relationships, which are negotiated according to individual goals and interests in a context of individualistic organization of family relationships. In this context, the developmental task is to focus on one's autonomy. This becomes more prevalent during and after adolescence, when adult daughters start a family of their own. They choose their partner on the basis of romantic attraction, while in traditional Asian countries the main goal is to serve the wishes and interests of the family, and to get married to someone who is accepted by the family (Mulder, 1992). Thus, forming a new family in Germany takes place in the context of individualistic values of autonomy and individual choice, in 
contrast to Indonesia, where a context of group-oriented values requires adult children to act in accordance with family interests.

When establishing a new family oneself, the parent-child relationship in the individualistic context becomes characterized by the goal of being freed from normative constraints, interference from and obligations to the descendant family in order to take responsibility for the new family as an independent new system. This does not, however, imply disconnected family ties over the life course; on the contrary, family relationships may still be based on emotional closeness and solidarity (Bengtson, 2001; Schwarz et al., 2005). In contrast, in the collectivistic context, marriage and children (the establishment of a new family) means the continuation of the existing family network by an extended in-group.

New developmental tasks emerge at this stage of development, such as the obligation to take care of parents as they age. According to Giarrusso et al. (1995), differences between the generations are still based on the lineage positions and not on differences in the individual developmental stages. The parent-child relationship over the life span has seldom been studied, and even more rarely been analysed in different cultures (Trommsdorff, 2006). According to the literature, in the collectivistic context the lifelong interconnectedness of parent-child relations acquires a new quality after marriage. Its stability increases especially since the next generation of grandchildren will be integrated as continuing the family line. For adult daughters, an increase in responsibility and obligation for the ageing parents lies ahead in both contexts. However, in a socially oriented context such as Indonesia the lifelong obligation of adult children to their parents, including filial piety, respect and support, is in stark contrast to the individualistic German context. Thus, the psychological conditions for adult children's dealing with their responsibility towards their parents are different in the two countries and characterize the culture-specific parent-child relationship over the life span. Our own earlier results on a higher individualism/independence of the German sample in contrast to a higher collectivism/interdependence of the Indonesian sample document the validity of the selection of different cultural samples (Albert et al., 2007; Mayer et al., 2004).

\section{Research Questions and Hypotheses}

On the basis of these notions, the present study deals with the following questions:

1. Do we find intergenerational differences in accordance with the intergenerational stake hypothesis in a western culture (Germany) as well as in an Asian culture (Indonesia)? We expect the differences to be larger in an individualistic culture like Germany than in a collectivistic culture like Indonesia. 
2. Above and beyond these mean comparisons, do we find different patterns of intergenerational differences in the two cultures?

3. Are certain cultural characteristics like value orientations related to the expected intergenerational differences? We expect that collectivistic or interdependent value orientations will be related to fewer intergenerational differences in mutual perception, and individualistic or independent orientations to be related to more differences.

\section{Methods}

\section{Procedure}

As part of the three-generational 'Value of Children and Intergenerational Relationship' study in 11 cultures (see Trommsdorff and Nauck, 2005), a total of 1000 participants from Germany and Indonesia each were interviewed. A convenient sampling method was used. In Indonesia, the participants were recruited via schools from two locations: in Bandung, a large city in West Java, and in a rural area where agricultural production still prevails (about $20-40 \mathrm{~km}$ from Bandung). In Germany, the participants were recruited through residents' registration offices from three different cities in Germany: Chemnitz, Essen and Konstanz.

The interviews were carried out individually with each person face-toface. The mothers and their daughters were interviewed by interviewers trained in the multi-thematic standardized interview. Each interviewee answered all questions in the assigned sequence. A small gift was presented at the end of the interview (for more details, see Albert et al. [2005] for the Indonesian sample, and Mayer et al. [2005] for the German sample).

\section{Participants}

For the following analyses, a smaller subsample consisting of 100 adult mother-daughter dyads from each culture is used in order to focus on a two-generational sample of mother-daughter dyads. The majority of the Indonesian sample was of Sundanese descent, the rest Javanese, and mostly Islamic, while a majority of the German women belonged to Christian churches.

Mothers and daughters from the Indonesian sample were significantly younger than their counterparts from Germany (mothers: $t=6.56$, d.f. $=180.94, p<.001$; daughters: $t=5.24$, d.f. $=198, p<.001$ ). The mean age of Indonesian mothers was 63.57 years $(\mathrm{SD}=7.82)$ compared to 70.06 years $(\mathrm{SD}=5.94)$ of the German mothers. The respective mean ages of the daughters were $40.08(\mathrm{SD}=4.92)$ and $43.59(\mathrm{SD}=4.54)$. Furthermore, the number of children was higher among the Indonesian mothers $(M=6.13$, $\mathrm{SD}=3.15)$ and daughters $(M=3.36, \mathrm{SD}=1.53)$ compared to the German 
mothers $(M=2.88, \mathrm{SD}=1.52 ; t=-9.30$, d.f. $=142.82, p<.001)$ and daughters $(M=2.37, \mathrm{SD}=.91 ; t=-5.56$, d.f. $=160.59, p<.001)$. Among the Indonesian mothers, 54.5 percent had not completed any schooling, 31.3 percent had a lower education and 14.1 percent a middle education. The Indonesian daughters were better educated, with only 9.1 percent without any school certificate, 44.4 percent with a lower, 38.4 percent with a middle and 8.1 percent with a higher education. All German mothers and daughters had finished secondary school. Among the mothers, 29 percent had a lower, 65.6 percent had a middle and 5.4 percent had a higher education. The respective figures for German daughters were 9.2 percent, 55.1 percent and 35.7 percent. Compared to national statistics, the German daughters were biased towards higher education.

Furthermore, the Indonesian mothers and daughters lived closer together as compared to the German dyads $(t=8.57$, d.f. $=183.85, p<.001)$, and the frequency of their contact (personal or by phone or mail) was higher $(t=6.47$, d.f. $=181.91, p<.001)$.

\section{Measures}

All measures used are based on standardized instruments, most of which had previously been used in cross-cultural studies (for a detailed description of the whole questionnaire including the specific instrument, see Schwarz et al., 2001). Self-reports of the adult daughters and elderly mothers were assessed for the variables described as follows.

\section{Quality of the Mother-Adult Daughter Relationship}

We selected three subscales of the Network of Relationship Inventory (NRI) (Furman and Buhrmester, 1985). Mothers and daughters reported on intimacy (e.g. How often do you tell your mother/daughter everything that is on your mind?), conflict (e.g. How often do you and your mother/daughter disagree and quarrel?) and admiration (e.g. How often does your mother/daughter let you know that you're good at things?) in their relationship. Additionally, emotional support (given to the daughter by the parents in the last 12 months reported from the perspective of the daughter and from the perspective of the mother, e.g. How often have they/have you given advice in the last 12 months?) was assessed. Each scale consisted of three items, the response format ranged from 1 (never) to 5 (always). The satisfying to good internal consistencies ranged between Cronbach's alpha $=.60$ and Cronbach's alpha $=.82$.

\section{Value Orientation}

Value orientations were assessed with two instruments measuring the collectivism/individualism and the interdependence/independence dimensions. A short version of the Individualism/Collectivism Scale by 
Schwartz and Bilsky (1990) was used, which was developed as part of the COLINDEX (Chan, 1994). The collectivism scale comprised six items (e.g. honour of your parents and elders [showing respect]) and the individualism scale, seven items (e.g. an exciting life [stimulating experiences]). Mothers and daughters rated the importance of each item on a five-point scale ranging from 1 (not important at all) to 5 (very important). The internal consistencies ranged between Cronbach's alpha $=.67$ and Cronbach's alpha $=.82$.

Interdependence (e.g. It is important to me to respect decisions made by my family) and independence (e.g. I enjoy being unique and different from family members in many respects) were assessed by a short version of the Self Construal Scale by Singelis (1994), developed and modified for the Value of Children study. After modification of the wording, the items referred to the respondents' family. The items were rated on a five-point scale from 1 (strongly disagree) to 5 (strongly agree). The internal consistencies for interdependence were satisfying or good (Cronbach's alpha between .60 and .77). The independence scale only reached high Cronbach's alpha for the mothers (Indonesia .64, Germany .60) but not for the daughters (Indonesia .43, Germany .45). Thus, in the following analyses independence of the daughters was omitted.

\section{Results}

\section{Intergenerational Differences in the Perception of the Relationship Quality in Germany and Indonesia}

In a first step of analyses, we investigated whether intergenerational differences in accordance with the intergenerational stake hypothesis could be found in Indonesia and Germany, i.e. whether the mothers had a more positive view of the relationship than their daughters. To test this question, analyses of variance for dependent measures with relationship quality perceived by daughter and mother (intimacy, conflict, admiration and emotional support) as dependent variables, generations as within-subject factor, and culture (Germany, Indonesia) as between-subject factor were conducted. Significant interactions of generation and culture point to cultural differences in the perception of the relationship by mothers and daughters. Furthermore, these analyses give information about overall generation and overall culture effects (see Table 1).

In three out of four indicators, an overall cultural difference occurred. Indonesian as compared to the German women reported less intimacy $(M=2.49$ vs $M=2.69)$, less admiration $(M=2.73$ vs $M=3.14)$, but more emotional support given to the daughter $(M=2.82$ vs $M=2.10)$. Above and beyond the interaction effects, we found only one overall intergenerational difference. Independent of culture, mothers perceived more intimacy 
Table 1 Analyses of Variance with Dependent Measures for Adult Mother-Daughter Relationship Quality (F-Values and Significance)

\begin{tabular}{lcccc}
\hline & Conflict & Intimacy & Admiration & Emotional support \\
\hline $\begin{array}{l}\text { Between subjects } \\
\text { Culture }(\mathrm{C})\end{array}$ & .45 & $3.93^{*}$ & $25.22^{* * *}$ & $70.42^{* * *}$ \\
Within subjects & & & & .45 \\
$\quad$ Generation $(\mathrm{G})$ & 2.32 & $10.45^{* * *}$ & .90 & .45 \\
$\mathrm{C} \times \mathrm{G}$ & $15.00^{* * *}$ & $4.67^{*}$ & .03 & $10.41^{* * *}$ \\
\hline
\end{tabular}

Note: d.f. $=1,197$.

${ }^{*} p<.05,{ }^{* * *} p<.001$.

in the relationships than daughters ( $M=2.70$ vs $M=2.47)$. This intergenerational difference was in line with the assumption of the intergenerational stake hypothesis.

Significant interactions occurred with respect to intimacy and conflict in the mother-daughter relationship and emotional support given to the daughter. No interaction of generation and culture was found for perceived admiration. With respect to intimacy and conflict, $t$-tests for dependent measures revealed intergenerational differences in accordance with the intergenerational stake hypothesis in the German sample only. The German mothers reported more intimacy $(M=2.88, \mathrm{SD}=.90$ vs $M=2.49, \mathrm{SD}=.83 ; t=4.65$, d.f. $=98, p<.001)$ and less conflict $(M=1.53$, $\mathrm{SD}=.47$ vs $M=1.77, \mathrm{SD}=.62 ; t=-4.56$, d.f. $=98, p<.001)$ than their daughters, while the two generations within the Indonesian sample did not differ (intimacy: $t=.66$, d.f. $=99$, NS; conflict: $t=1.46$, d.f. $=99$, NS). These results are in line with our expectation that intergenerational differences in the perception of the relationship quality only occur in more individualistic cultures where values of independence prevail.

However, the data on emotional support given to the daughter revealed an opposite pattern. Here, only in Indonesia did an intergenerational difference in accordance with the intergenerational stake hypothesis occur. The degree of emotional support Indonesian mothers reported offering was higher $(M=2.95, \mathrm{SD}=.92)$ than the amount of emotional support daughters reported receiving $(M=2.69, \mathrm{SD}=.76 ; t=-2.25$, d.f. $=99$, $p<.05)$. In the German sample, a significant intergenerational difference resulted $(t=2.57$, d.f. $=98, p<.05)$, however, with an opposite pattern. Here, mothers reported giving less emotional support $(M=2.01, \mathrm{SD}=.67)$ than the daughters reported receiving $(M=2.18, \mathrm{SD}=.67)$. Thus, our general expectation that the intergenerational stake hypothesis is only valid for individualistic or modernized cultures needs further differentiation. For 
a deeper understanding, in a second step of analyses we analysed the patterns of differences between the generations.

\section{Patterns of Intergenerational Differences}

As Giarrusso et al. (1995) and Aquilino (1999) showed, the simple focus on mean differences between generations can obscure the variety of patterns that lay behind those results. In the study by Giarrusso et al. (1995), 15-28 percent of the sample showed a pattern where children's affection for parents was higher than the reverse. Almost one-quarter of the sample in the study by Aquilino (1999) belonged to a cluster with a similar pattern. In order to test whether our samples also include dyads with patterns of intergenerational differences that do not fit the intergenerational stake hypothesis, we computed difference scores (mother's report minus daughter's report) and conducted cluster analyses across the difference scores. In order to indicate the appropriate number of clusters, we followed the suggestions of Wiedenbeck and Züll (2001) and first conducted hierarchical cluster analyses across the four difference scores for intimacy, admiration, conflict and emotional support, choosing Ward's method. According to the analysis, a two- or three-cluster solution was appropriate. Since the literature suggested three patterns (mother positive, equal, daughter positive) we chose the three-cluster solution. In a second step, we used K-means cluster analyses to improve the classification of the intergenerational differences into the three clusters. The means of the difference score for the dyads assigned to the three clusters are shown in Table 2.

According to these means, Cluster 1 fits best with the intergenerational stake hypothesis with a more positive view held by mothers than by daughters concerning intimacy, admiration and emotional support, while both generations agreed about conflict in their relationship. Cluster 2 was in most instances the opposite of Cluster 1 and was best described as 'Daughter perceives the relationship more positively than the mother'. This was true for intimacy, admiration and emotional support but not for conflict. Contrary to the other indicators, daughters in this cluster reported more conflicts than the mothers, though the difference score was small. Cluster 3 was not characterized by high agreement, as in the study by Aquilino (1999). Instead, this cluster was characterized by a high negative discrepancy between intimacy reported by mothers and reported by daughters. Since the intimacy items assessed how much selfdisclosure the respective person was willing to engage in, Cluster 3 reflects dyads with a mother who displayed less self-disclosure as compared to the daughter. Simultaneously, these dyads showed several characteristics consistent with the pattern predicted by the intergenerational stake hypothesis: the mothers in Cluster 3 reported less conflict, more admiration and more emotional support than their daughters. 
Table 2 Means of the Four Mother-Daughter Difference-Scores for the Three Clusters

\begin{tabular}{lccc}
\hline & $\begin{array}{c}\text { Cluster } 1 \\
\text { Mother more } \\
\text { positive than } \\
\text { daughter }\end{array}$ & $\begin{array}{c}\text { Cluster 2 } \\
\text { Daughter more } \\
\text { positive than } \\
\text { mother }\end{array}$ & $\begin{array}{c}\text { Cluster } 3 \\
\text { Less } \\
\text { self-disclosure } \\
\text { of mother }\end{array}$ \\
\hline Conflict & .09 & -.13 & -.18 \\
Intimacy & 1.20 & -.20 & -.47 \\
Admiration & .60 & -.56 & .26 \\
Emotional support & .30 & -.56 & .60 \\
$N$ & 71 & 77 & 51 \\
\hline
\end{tabular}

Note: Positive differences refer to mothers reporting higher scores than daughters, negative differences refer to daughters reporting higher scores than mothers, and scores around zero refer to similarities between the generations.

${ }^{a}$ Consistent with the intergenerational stake hypothesis.

\section{Prediction of Intergenerational Differences by Culture and Value Orientations}

By comparing the German and Indonesian samples, we attempted to compare dyads from a more individualistic and a more collectivistic culture. In fact, Indonesian mothers favoured values of interdependence to a significantly higher extent and tended to be less individualistic and more collectivistic as compared to German mothers. However, the mothers from both cultures did not differ with respect to independence. The daughters from Indonesia favoured values of collectivism and interdependence significantly more than the German daughters. However, the daughters from both cultures did not differ with respect to individualism.

Additionally, we expected that individualistic and independent orientations would be associated with larger intergenerational differences, particularly those which are in accordance with the intergenerational stake hypothesis, while collectivistic and interdependent orientations would be associated with smaller differences. Therefore, we investigated whether culture and individual value orientations predicted the cluster assignments.

A cross-table showed that 52 percent of the dyads in Cluster 1 (mother more positive) were from Germany and 48 percent from Indonesia and comparable numbers (54 percent vs 46 percent) were shown for the opposite Cluster 2 (daughter more positive). Only 39 percent of the dyads in Cluster 3 (less self-disclosure of mother) were from Germany as compared to 61 percent from Indonesia, however, the difference was not significant $\left(\chi^{2}=3.13[2, N=199] \mathrm{NS}\right)$.

To predict the assignment to specific clusters, multinomial logistic regressions were conducted with culture and value orientations as 
Table 3 Multinomial Logit Model Predicting Cluster Membership in Comparison to the 'Less Self-Disclosure of Mother' Cluster from Geographical Distance, Collectivism and Culture

\begin{tabular}{lrccr}
\hline & B & SE B & Wald & Exp(B) \\
\hline $\begin{array}{l}\text { CL: Mother more positive } \\
\text { than daughter }\end{array}$ & & & & \\
Geographical distance & -.01 & .18 & .00 & .99 \\
Collectivism $^{a}$ & .89 & .44 & $4.09^{*}$ & 2.45 \\
Culture $^{b}$ & .57 & .45 & 1.59 & 1.77 \\
CL: Daughter more positive & & & & \\
than mother & & & & \\
Geographical distance & -.17 & .18 & .92 & .84 \\
Collectivism & .23 & .41 & .31 & 1.26 \\
Culture $^{b}$ & .80 & .44 & $3.37+$ & 2.23 \\
\hline
\end{tabular}

Notes:

${ }^{a}$ Consistent with the intergenerational stake hypothesis.

${ }^{b} 1=$ Germany, 2 = Indonesia.

$+p<.07,{ }^{*} p<.05$.

predictors and geographical distance as a control variable. Cluster 3, which was different to clusters found in the US studies, was chosen as the reference group. The multinomial logistic regression estimates simultaneously the likelihood of a dyad to fall into the 'mother more positive' cluster or the 'daughter more positive' cluster versus the 'less self-disclosure of mother' cluster. The coefficients indicate the tendency of the dyad to fall into the 'less self-disclosure of mother' cluster. All value indicators that had no significant effects were dropped, leaving one indicator: mothers' collectivism. As indicated in Table 3, geographical distance did not play a role. Additionally, the likelihood of falling into the 'less self-disclosure of mother' cluster instead of the 'daughter more positive' cluster was not affected by maternal collectivism but, at least as a tendency, by culture. The Indonesian dyads showed a higher likelihood of belonging to the 'less self-disclosure of mother' cluster than to the 'daughter more positive' cluster as compared to the German dyads. Furthermore, the likelihood of a dyad belonging to the 'less selfdisclosure of mother' cluster versus the 'mother more positive' cluster was influenced by maternal collectivism but not by culture. The higher the mothers' collectivism, the higher their likelihood of belonging to the 'less self-disclosure of mothers' cluster. In sum, it seems that the 'less self-disclosure of mother' cluster was more typical for Indonesian mother-daughter dyads and for dyads in which mothers were high in collectivism. 


\section{Discussion}

To summarize the results, the intergenerational stake hypothesis was only partly confirmed. Three types of analyses were performed to examine the research questions. The results on mean differences for the German mother-daughter dyads with respect to intimacy and conflict supported the intergenerational stake hypothesis, while emotional support given by the mother was more frequently reported by mothers than daughters in the Indonesian sample. Thus, the intergenerational stake hypothesis should be specified with regard to the aspects of the relationship quality that are subjectively evaluated by both generations.

The results on mean differences among evaluations of mothers and their adult daughters are only one aspect of a complete analysis of intergenerational relations. Assuming that these means may be based on different patterns, we carried out a cluster analysis including difference scores of the four indicators of relationship quality. The results revealed three different patterns, of which only one was consistent with the intergenerational stake hypothesis. Of the entire sample, 35 percent of mothers perceived the relationship more positively than their daughters. A second cluster comprised 39 percent of the mother-daughter dyads and can be characterized as the opposite pattern, where daughters perceived the relationship more positively than their mothers. A third cluster comprised 26 percent of the dyads and was characterized by lower selfdisclosure of the mother compared to the daughter. Indonesian dyads tended to have a higher likelihood of belonging to the last cluster as compared to the second cluster. Maternal collectivism was also associated with a higher likelihood of belonging to this cluster. Furthermore, our results have demonstrated clear differences in value orientations between the more individualistic German and the more interdependent/socially oriented Indonesian samples in the expected direction.

The similarities between the cultures with respect to maternal independence and daughters' individualism indicate that individualistic/independent tendencies also occur in the Indonesian sample.

\section{Differential Confirmation of the Intergenerational Stake Hypothesis}

The intergenerational stake hypothesis was confirmed only in the German sample with respect to intimacy and conflict and only in the Indonesian sample with respect to emotional support given by the mother. The items on intimacy in our study refer to the tendency of the participants to open themselves up in the relationship (talk about own sorrow or communicate personal experiences). Self-disclosure is a more relevant communication style in individualistic cultures than in collectivistic cultures. High self-disclosure by 
mothers in the relationship with their daughters might be a less acceptable behaviour in collectivistic cultures where clear role definitions regulate interactions. This interpretation is supported by our data, which showed that less maternal self-disclosure is more typical among dyads with collectivistic mothers.

Furthermore, in line with the often reported cultural value of harmony in the Javanese family (e.g. Geertz, 1961, 1974; Magnis-Suseno, 1997; Mulder, 1996), less conflict between Indonesian as compared to German mothers and daughters and no intergenerational difference in the perception of this aspect among the Indonesian dyads occurred in our study. Possibly, the respect for the older generation in Indonesia inhibits the younger generation from experiencing conflict or complaining about conflict with parents. This interpretation is reaffirmed by the result that Indonesian daughters report less conflict with mothers than do German daughters (statistical results not reported here due to space limitation). Thus, the finding that the intergenerational stake hypothesis was confirmed with respect to intimacy and conflict only in the German sample is in line with the cultural values regarding the intergenerational relationship.

When it comes to other aspects of the relationship, like the emotional support the mother has given to her daughter, Indonesian mothers' reports were more positive than those of their daughters. To give support and help to the children is part of Javanese ethics (Magnis-Suseno, 1997). Based on the value of interdependence, this tendency prevails throughout the life span in the Indonesian context. Even if transfer of support from parents to children is an ordinary phenomenon in Germany (Kohli et al., 2000), we assume that help and support given to the adult children is more highly valued by Indonesian than by German mothers. This may explain the asymmetric reports about emotional support in the Indonesian dyads.

The patterns of intergenerational differences were only partly affected by culture. Consistent with the intergenerational stake hypothesis, similar percentages of mother-daughter dyads were observed in the German and in the Indonesian sample in Cluster 1 . The same was true for the opposite pattern, in which daughters had a more positive view of the relationship. Only with respect to the pattern of less maternal self-disclosure were the Indonesian dyads somewhat overrepresented. This fits with our earlier explanation that the culture-specific role definition and collectivistic values undermine an individualistic communication style characterized by self-disclosure.

\section{Role of Value Orientations to Explain the Intergenerational Stake Hypothesis}

Although differences in value orientations between the German and Indonesian samples occurred in the expected direction, the correlations of 
the various value orientations with patterns of intergenerational differences were not strong. However, in line with our argumentation, the more the mothers preferred collectivistic values, the higher the probability that the mother-daughter dyad was characterized by the pattern with less maternal self-disclosure. Our expectation that the intergenerational stake pattern is more frequent among individualistic or independently oriented dyads was not confirmed by this study. Our results rather pointed to different patterns of intergenerational relations, which partly overlap with cultural membership and value orientation.

It therefore seems to be too simple to assume that parents always view their relationship with their children more positively than do the children. Though it is well known that parents and children may differ in the way they perceive their relationship, the factors underlying this difference are less well known. These factors may include past experience, futureoriented expectations, social comparison processes (with other parent-child dyads) and, of course, person variables. Beyond these, cultural values also guide the mutual perception and thereby affect such reports. Also, the verbal reports are coloured by cultural values of socially desirable answers for both generations. Further research should search for theoretically relevant variables to explain some of the variance in perceptual differences.

A focus on value orientations seems to be a promising start. When comparing samples with different preferences for collectivistic and individualistic values in sociocultural contexts that are undergoing massive changes, one should refrain from the simple one-dimensional approach. A focus on different patterns of combinations in collectivism and individualism may be more appropriate in order to take into account possible changes in value orientation that are adaptive to ongoing social change and that affect the parent-child relationship. A certain degree of autonomy or independence may be quite adaptive in either individualistic or collectivistic societies (Rothbaum and Trommsdorff, 2007). Taking into account also the relative importance of relatedness or interdependence and its possible culture-specific meaning may therefore allow us to clarify different patterns (in the perception) of intergenerational relations.

\section{Conclusions}

Our cross-cultural comparisons clearly demonstrate that more culturesensitive differentiations of the intergenerational stake hypothesis are necessary in future research. In line with a cultural value perspective, parent-child relationships and their development follow culture-specific pathways (Rothbaum et al., 2000). The results presented here are based on analyses of the data from the cross-national Value of Children (VOC) study, which focuses on intergenerational relations. Further analyses are 
currently being undertaken and are needed to better understand the cultural differences as well as similarities in intergenerational relationships. These analyses will in general follow the theoretical model that underlies the ongoing VOC study (see Trommsdorff, 2001), taking into account the intergenerational similarities and differences in value orientations (and their relative importance) to explain intergenerational differences in the perception of the relationship quality. Further variables, such as sociodemographic indicators (e.g. education or job status) as well as personal characteristics like attachment and socialization experiences will be included in these analyses.

Cross-cultural studies such as this one can demonstrate the limitations of previous studies on intergenerational relations focused entirely on western samples. Obviously, culture-specific patterns in intergenerational relations have to be taken into account to differentiate the intergenerational stake hypothesis. The way adult daughters and their mothers perceive their relationship depends on the cultural context and, more specifically, on the value orientations that have been socialized in the specific culture.

Therefore, since the quality of the parent-child relationship influences parent-child interactions, including the willingness of parents and adult children to sacrifice certain resources and give (mutual) support in case of need, the question may be raised: to what degree will the present value orientations be transmitted to the next generation and affect the quality of the relationship between parents and their children over the life span?

\section{Note}

This research was supported by grants from the Deutsche Forschungsgemeinschaft (TR 169/9-1, 2, 3) to the first author. The project is part of the study 'Value of Children Revisited' (principal investigators: Gisela Trommsdorff, University of Konstanz and Bernhard Nauck, Technical University of Chemnitz). The Indonesian study was directed by Lieke Wisnubrata and the Bandung team: Samsunuwijati Marat, Kusdwiratri Setiono and Peter R. Nelwan. The German data were collected by the Chemnitz and the Konstanz team headed by the principal investigators.

\section{References}

Albert, I., Trommsdorff, G., Mayer, B. and Schwarz, B. (2005) ‘Value of Children in Urban and Rural Indonesia: Socio-Demographic Indicators, Cultural Aspects and Empirical Findings', in G. Trommsdorff and B. Nauck (eds) The Value of Children in Cross-Cultural Perspective: Case Studies from Eight Societies, pp. 171-208. Lengerich: Pabst Science. 
Albert, I., Trommsdorff, G. and Wisnubrata, L. (2007) 'Intergenerational Transmission of Values in Different Cultural Contexts: A Study in Germany and Indonesia', submitted to the Proceedings of the 18th International Congress of the International Association for Cross-Cultural Psychology (IACCP), Spetses, Greece.

Aquilino, W. S. (1999) 'Two Views of One Relationship: Comparing Parents' and Young Adult Children's Reports of the Quality of Intergenerational Relations', Journal of Marriage and the Family 61(4): 858-70.

Bengtson, V. L. (2001) 'Beyond the Nuclear Family: The Increasing Importance of Multigenerational Bonds', Journal of Marriage and Family 63(1): 1-16.

Bengtson, V. L. and Kuypers, J. A. (1971) 'Generational Difference and the Developmental Stake', Aging and Human Development 2(4): 249-60.

Bond, J. B. and Harvey, C. D. (1991) 'Ethnicity and Intergenerational Perceptions of Family Solidarity', International Journal of Aging and Human Development 33(1): 33-44.

Chan, D. K.-S. (1994) 'Colindex: A Refinement of Three Collectivism Measures', in U. Kim, H. C. Triandis, C. Kağitçibaşi, S.-C. Choi and G. Yoon (eds) Individualism and Collectivism: Theory, Method, and Applications, pp. 200-210. Thousand Oaks, CA: Sage.

Dasen, P. (2007) 'Ein integrativer theoretischer Rahmen menschlicher Entwicklung aus öko-kultureller Perspektive' [An Integrative Theoretical Frame of Human Development from an Eco-Cultural Perspective], in G. Trommsdorff and H.-J. Kornadt (eds) Enzyklopädie der Psychologie. Theorien und Methoden der kulturvergleichenden Psychologie, Vol. 1, pp. 535-54. Göttingen and Toronto: Hogrefe.

Fiske, A. P., Kitayama, S., Markus, H. R. and Nisbett, R. E. (1998) 'The Cultural Matrix of Social Psychology', in D. T. Gilbert, S. T. Fiske and G. Lindzey (eds) The Handbook of Social Psychology, Vol. 2, 4th edn, pp. 915-81. Boston, MA: McGraw-Hill.

Furman, W. and Buhrmester, D. (1985) 'Children's Perceptions of the Personal Relationships in their Social Networks', Developmental Psychology 21(6): 1016-24.

Geertz, H. (1961) The Javanese Family: A Study of Kinship and Socialization. Prospect Heights, IL: Waveland Press.

Geertz, H. (1974) 'The Vocabulary of Emotion: A Study of Javanese Socialization Processes', in R. A. LeVine (ed.) Culture and Personality, pp. 249-64. Chicago, IL: Aldine.

Giarrusso, R., Stallings, M. and Bengtson, V. L. (1995) 'The "Intergenerational Stake" Hypothesis Revisited: Parent-Child Differences in Perceptions of Relationships 20 Years Later', in V. L. Bengtson, W. K. Schaie and L. M. Burton (eds) Adult Intergenerational Relations: Effects of Societal Changes, pp. 229-96. New York: Springer.

Greenfield, P., Keller, H., Fuligni, A. and Maynard, A. (2003) 'Cultural Pathways through Universal Development', Annual Review of Psychology 54: 461-90.

Hofstede, G. H. (2000) Culture's Consequences: International Differences in WorkRelated Values, 5th edn. Newbury Park, CA: Sage.

Hofstede, G. H. (2007) 'Der kulturelle Kontext psychologischer Prozesse' [The Cultural Context of Psychological Processes], in G. Trommsdorff and H.-J. 
Kornadt (eds) Enzyklopädie der Psychologie. Theorien und Methoden der kulturvergleichenden Psychologie, Vol. 1, pp. 385-405. Göttingen and Toronto: Hogrefe.

Kağitçibaşi, C. (1996) Family and Human Development across Cultures: A View from the Other Side. Mahwah, NJ: Lawrence Erlbaum Associates.

Kitayama, S., Karasawa, M. and Mesquita, B. (2004) 'Collective and Personal Processes in Regulating Emotions: Emotion and Self in Japan and the United States', in P. Philippot and R. S. Feldman (eds) Regulation of Emotion, pp. 251-73. Mahwah, NJ: Lawrence Erlbaum Associates.

Kohli, M., Künemund, H., Motel, A. and Szydlik, M. (2000) 'Families Apart? Intergenerational Transfer in East and West Germany', in S. Arber and C. Attias-Donfut (eds) The Myth of Generational Conflict: The Family and State in Ageing Societies, pp. 88-99. London: Routledge.

Magnis-Suseno, F. (1997) Javanese Ethics and World View: The Javanese Idea of the Good Life. Jakarta: Gramedia Pustaka Utama.

Markus, H. R. and Kitayama, S. (1991) 'Culture and the Self: Implications for Cognition, Emotion, and Motivation', Psychological Review 98: 224-53.

Markus, H. R. and Kitayama, S. (1994) 'The Cultural Construction of Self and Emotion: Implications for Social Behavior', in S. Kitayama and H. R. Markus (eds) Emotion and Culture: Empirical Studies of Mutual Influence, pp. 89-130. Washington, DC: American Psychological Association.

Mayer, B., Albert, I., Trommsdorf, G. and Schwarz, B. (2005) 'Value of Children in Germany: Dimensions, Comparison of Generations, and Relevance for Parenting', in G. Trommsdorff and B. Nauck (eds) The Value of Children in Cross-Cultural Perspective: Case Studies from Eight Societies, pp. 43-66. Lengerich: Pabst Science.

Mayer, B., Trommsdorff, G., Wisnubrata, L. and Setiono, K. (2004) 'A Comparison of Indonesian and German Adolescents' Family Models', in G. Trommsdorff (Convenor), 'Value of Children and Intergenerational Relations in Different Cultures (Part II)' symposium conducted at the 17th International Congress of the International Association for Cross-Cultural Psychology, Xi'an, China, August.

Mesquita, B. and Markus, H. R. (2004) 'Culture and Emotion: Models of Agency as Sources of Cultural Variation in Emotion', in A. S. R. Manstead, N. Frijda and A. Fischer (eds) Feelings and Emotions: The Amsterdam Symposium, pp. 341-58. Cambridge: Cambridge University Press,

Mulder, N. (1992) Individual and Society in Java: A Cultural Analysis. Yogyakarta: Gadjah Mada University Press.

Mulder, N. (1996) Inside Indonesia Society: Cultural Change in Indonesia. Amsterdam: Pepin Press.

Oyserman, D., Coon, H. M. and Kemmelmeier, M. (2002) 'Rethinking Individualism and Collectivism: Evaluation of Theoretical Assumptions and Meta-Analyses', Psychological Bulletin 128: 3-72.

Rothbaum, F. and Trommsdorff, G. (2007) ‘Do Roots and Wings Complement or Oppose One Another? The Socialization of Relatedness and Autonomy in Cultural Context', in J. E. Grusec and P. Hastings (eds) The Handbook of Socialization, pp. 461-89. New York: The Guilford Press.

Rothbaum, F., Weisz, J., Pott, M., Miyake, K. and Morelli, G. (2000) 'Attachment and Culture: Security in the United States and Japan', American Psychologist 55: 1093-104. 
Schaie, K. W. and Willis, S. L. (1995) 'Perceived Family Environments across Generations', in V. L. Bengtson, K. W. Schaie and L. M. Burton (eds) Adult Intergenerational Relations, pp. 174-209. New York: Springer.

Schwartz, S. H. and Bilsky, W. (1990) 'Toward a Theory of the Universal Content and Structure of Values: Extensions and Cross-Cultural Replications', Journal of Personality and Social Psychology 58: 878-91.

Schwarz, B., Chakkarath, P. and Trommsdorff, G. (2002) 'Generationenbeziehungen in Indonesien, der Republik Korea und Deutschland' [Intergenerational Relationships in Indonesia, the Republic of Korea and Germany], Zeitschrift für Soziologie der Erziehung und Sozialisation 22(4): 393-407.

Schwarz, B., Chakkarath, P., Trommsdorff, G., Schwenk, O. and Nauck, B. (2001) 'Report on Selected Instruments of the Value of Children (Main Study)', unpublished manuscript.

Schwarz, B., Trommsdorff, G., Albert, I. and Mayer, B. (2005) 'Adult Parent-Child Relationships: Relationship Quality, Support, and Reciprocity', Applied Psychology: An International Review 54: 396-417.

Singelis, T. M. (1994) 'The Measurement of Independent and Interdependent SelfConstruals', Personality and Social Psychology Bulletin 20: 580-91.

Triandis, H. C. (1995) Individualism and Collectivism. Boulder, CO: Westview Press.

Trommsdorff, G. (1995) ‘Parent-Adolescent Relations in Changing Societies: A CrossCultural Study', in P. Noack and M. Hofer (eds) Psychological Responses to Social Change: Human Development in Changing Environments, pp. 189-218. Berlin: De Gruyter.

Trommsdorff, G. (2001) 'Value of Children and Intergenerational Relations: A CrossCultural Psychological Study'; at: www.uni-konstanz.de/FuF/SozWiss / fg-psy/ag-entw /

Trommsdorff, G. (2006) 'Parent-Child Relations over the Life-Span. A CrossCultural Perspective', in K. H. Rubin and O. B. Chung (eds) Parenting Beliefs, Behaviors, and Parent-Child Relations: A Cross-Cultural Perspective, pp. 143-83. New York: Psychology Press.

Trommsdorff, G. and Kornadt, H.-J. (2003) 'Parent-Child Relations in CrossCultural Perspective', in L. Kuczynski (ed.) Handbook of Dynamics in Parent-Child Relations, pp. 271-306. Thousand Oaks, CA: Sage.

Trommsdorff, G. and Nauck, B. (eds) (2005) The Value of Children in Cross-Cultural Perspective: Case Studies from Eight Societies. Lengerich: Pabst Sciences.

United Nations Statistics Division (2004) 'Handbook on Poverty Statistics: Concepts, Methods and Policy Use'; at: unstats.un.org/unsd/methods/poverty

Wiedenbeck, M. and Züll, C. (2001) Klassifikationen mit Clusteranalysen. Grundlegende Techniken hierarchischer und K-means-Verfahren [Classification with Cluster Analyses: Basic Techniques of Hierarchical and K-Means Procedures], ZUMA How-to-Reihe, No. 10. Mannheim, Germany: ZUMA.

Williams, W. (1991) Javanese Lives: Men and Women in Modern Indonesian Society. New Brunswick, NJ: Rutgers University Press.

Gisela Trommsdorff holds the Chair for Developmental and Cross-Cultural Psychology at the University of Konstanz, Germany (since 1987). Her research 
interests cover cross-cultural psychology, future orientation, life span development, intergenerational relationships, social change, subjective developmental theories, motivation and intentionality.

Address: Department of Psychology, Post Box D14, University of Konstanz, 78457 Konstanz, Germany. [email: Gisela.Trommsdorff@uni-konstanz.de]

Beate Schwarz is assistant professor at the University of Basle, Switzerland. Her main research interests focus on social relationships and problem behaviour in adolescence, children and adolescents in divorced and stepfamilies, parent-child relationships in adulthood and cross-cultural psychology.

Address: Department of Psychology, University of Basle, Missionsstr. 62a, 4055 Basle, Switzerland. [email: beate.schwarz@unibas.ch] 